\title{
DEVELOPMENT OF A TEST-RIG FOR A MODERN MOTORCYCLE ENGINE
}

\author{
Khalaf I. Hamada ${ }^{1}$, M.K.Mohammed ${ }^{1}$ and M.M. Rahman ${ }^{2,3}$ \\ ${ }^{1}$ Department of Mechanical Engineering, College of Engineering, \\ University of Tikrit, Tikrit, Iraq \\ Email:hamada.khalaf9@gmail.com \\ ${ }^{3}$ Faculty of Mechanical Engineering, Universiti Malaysia Pahang, \\ 26600 Pekan, Pahang, Malaysia \\ Email: mustafizur@ump.edu.my \\ Phone: +6094246239; Fax: +6094246222 \\ ${ }^{3}$ Automotive Engineering Centre, Universiti Malaysia Pahang, \\ 26600 Pekan, Pahang, Malaysia
}

\begin{abstract}
This paper presents experimental activities that have been performed in the Automotive Engineering Centre laboratories in Universiti Malaysia Pahang for developing a test-rig based on a modern motorcycle engine. The experimental engine test-rig was developed based on an eddy current dynamometer which was coupled to a four-stroke singlecylinder SI motorcycle engine. Moreover, the test-rig consists of all the measurement equipment, sensors and auxiliaries kits for carrying out engine testing in a sufficient way. The results of these activities have been used for validation of a one-dimensional model developed based on that single cylinder engine. Both the in-cylinder pressure trace and brake torque were used to validate the engine model. There was good agreement between the simulation and experimental results. The constructed test-rig can be utilized for further research and development programs.
\end{abstract}

Keywords: Small engine; test-rig; motorcycle; port injection

\section{INTRODUCTION}

The motorcycle is a very popular vehicle for transportation due to its mobility, convenience, economy, and door-to-door functions [1]. However, motorcycles are also a major source of air pollution and contribute to greenhouse gas emissions that cause climate change [2-6]. The technology roadmap for motorcycles in response to the increasing requirement for emission control and enhanced products is closely following that of the automotive industry [7-12]. Various challenges and drawbacks have arisen with the traditional IC engine technologies. Consequently, universal automotive engine researchers are concerned with the enhancement fuel efficiency to meet stringent emission limits [13-16]. One of the key areas of development in the modern automotive industry is fuel injection technology. It has provided considerable improvements towards realizing the concept of fuel efficiency (the lowest possible fuel consumption and emissions) over the last three decades. With respect to carburetion, fuel injection offers many advantages that design engineers have to evaluate for their cost effectiveness [17-19]. The fuel injection system utilizes a nozzle valve which is called an injector to spray fuel into the air stream [20,21]. Spark ignition engines use fuel injectors to spray fuel into the air stream into the intake manifold (throttle body 
injection), inlet port (port fuel injection), or directly into the cylinder (direct injection) [22]. Port fuel injection gives more increments in power and torque and more uniform fuel distribution, more rapid engine response to changes in throttle position, and more precise control of the equivalence ratio during cold-start and engine warm-up [23].Though the port fuel injection system has some advantages, it cannot at present meet the continuously increasing demands for performance, emission legislation and fuel economy [24]. Therefore, electronically controlled gasoline direct injection systems have started to be used instead of the port fuel injection system. Nevertheless, the port fuel injection (PFI) system has been used widely for small four-stroke gasoline engines because of its simplicity compared to the direct injection (DI) system [1, 25]. This research presents the design and construction of a simple practical test-rig based on the small engine for a modern motorbike application. With this modern engine, the port injection technique will be facilitated to convey new technologies for carrying out confirmed researches. It utilizes the existing equipment in the lab combined with the current technologies in the motorcycle field to develop an appropriate test-rig to support the institute's development and teaching programs.

\section{MATERIALS AND METHODS}

This research activity is conducted to build up an experimental test-rig based on a modern motorcycle engine for research and development purposes. Design work was started with the identification of which engine configuration could achieve the study targets; on the other hand it should be compatible with the existing equipment in the lab. Accordingly, the dynamometer was the key component for designing the current testrig. It was decided to consider the dynamometer's specifications to determine a suitable engine configuration.

\section{Dynamometer}

An eddy current dynamometer manufactured by Dynalec Controls Ltd. with a capacity of $15 \mathrm{~kW}$ was used. Figure 1 shows the dynamometer coupled to the installed test engine and cooling systems. A universal propeller shaft was used to transfer the energy from the engine to the dynamometer. The control system of the dynamometer was mounted in the control room as shown in Figure 2. From the dynamometer control panel, the required operation mode is specified among seven available modes. In addition, the throttle controller is actuated and the required position is selected (WOT). It is also possible to impose the required engine speed and read the torque produced by the engine. Throttle control is one of the basic controls required for the engine testing. A Dynalec Controls TLPC/612A control unit and TM/612B throttle actuator were utilized in this work.

\section{Tested Engine}

The tested engine is a motorbike engine with a port gasoline fuel injection system (model Yamaha FZ150i) manufactured by Yamaha-Malaysia. It is a single cylinder, four-stroke, naturally aspirated, water-cooled motorcycle engine. The aluminium cylinder head has a pent-roof configuration for the combustion chamber with a centremounted sparkplug. The cylinder head has dual intake and exhaust valves actuated by a single overhead cam (SOHV). The engine is representative of the small engine group. 
The engine specifications are listed in Table 1. The engine with the eddy current dynamometer engine test-rig is shown in Figure 1. The engine cooling system was modified in order to carry out the experiment. The base engine radiator was disconnected and engine coolant is taken directly to the external cooling system. An engine water pump circulates the coolant between the engine and the external cooling system rather than an engine radiator. The external cooling system is made up of a three-way valve and a header tank heat exchanger. This three-way valve governs the flow direction according to the temperature signal. It is actuated by a pneumatic actuator manufactured by Young Tech Ltd. The header tank is a shell and tube heat exchanger with the engine coolant being the fluid flowing into the tube. The temperature of the coolant expelled from the engine is sensed by a thermocouple which transmitsa signal to the temperature controller. The pre-set temperature specified for the controller was $70^{\circ} \mathrm{C}$ to match the manufacturer's settings. The rejected heat from the coolant in the header tank heat exchanger is carried by the water and rejected ultimately in a fan coil heat exchanger.

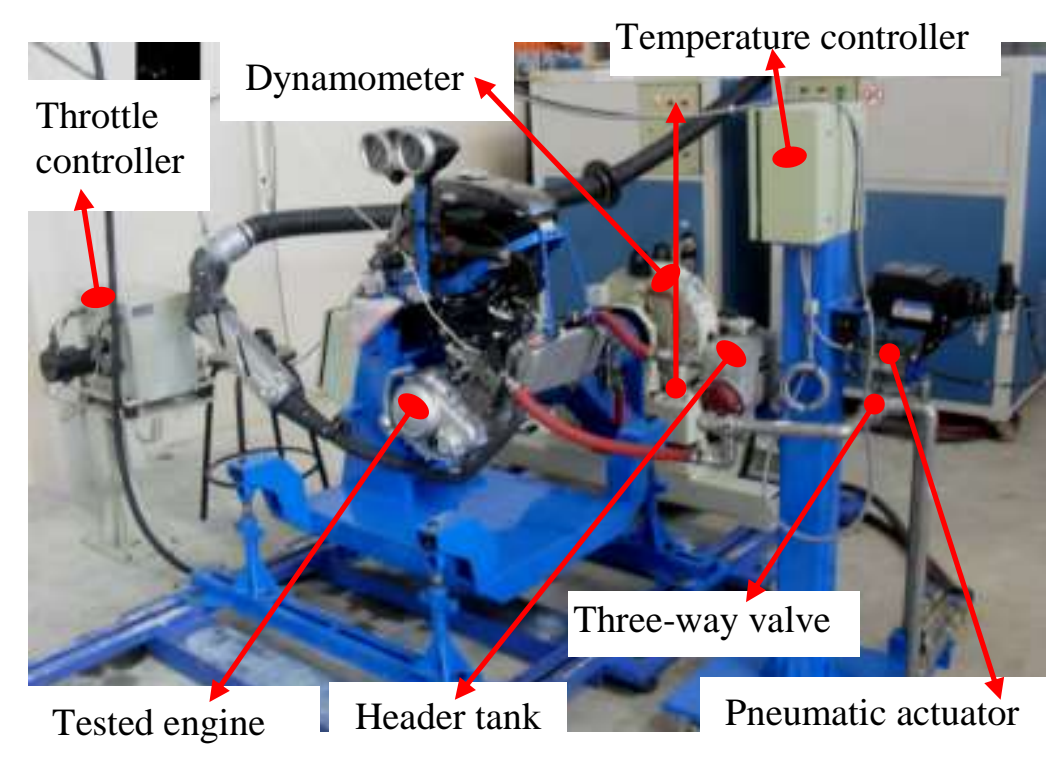

Figure 1. Test engine connected to the eddy current dynamometer.

Table 1. Specifications of the selected test engine.

\begin{tabular}{ll}
\hline Parameter & Value \\
\hline Engine model & 4 -stroke, water cooled, spark ignition, port injection \\
Bore $\times$ stroke $\left[\mathrm{mm}^{3} \times \mathrm{mm}\right]$ & $57 \times 58.7$ \\
Displacement $\left[\mathrm{cm}^{3}\right]$ & 149.8 \\
Geometric compression ratio & 10.4 \\
Connecting rod length $[\mathrm{mm}]$ & 100 \\
Intake valve open/ closed & $29^{\circ} \mathrm{BTDC} / 59^{\circ} \mathrm{ABDC}$ \\
Exhaust valve open/ closed & $57^{\circ} \mathrm{BBDC} / 29^{\circ} \mathrm{ATDC}$ \\
Max. power $[\mathrm{kW}]$ & $11.1 @ 8500[\mathrm{rpm}]$ \\
Max. torque $[\mathrm{N} . \mathrm{m}]$ & $13.1 @ 7500[\mathrm{rpm}]$ \\
No. of cylinder & 1 \\
\hline
\end{tabular}




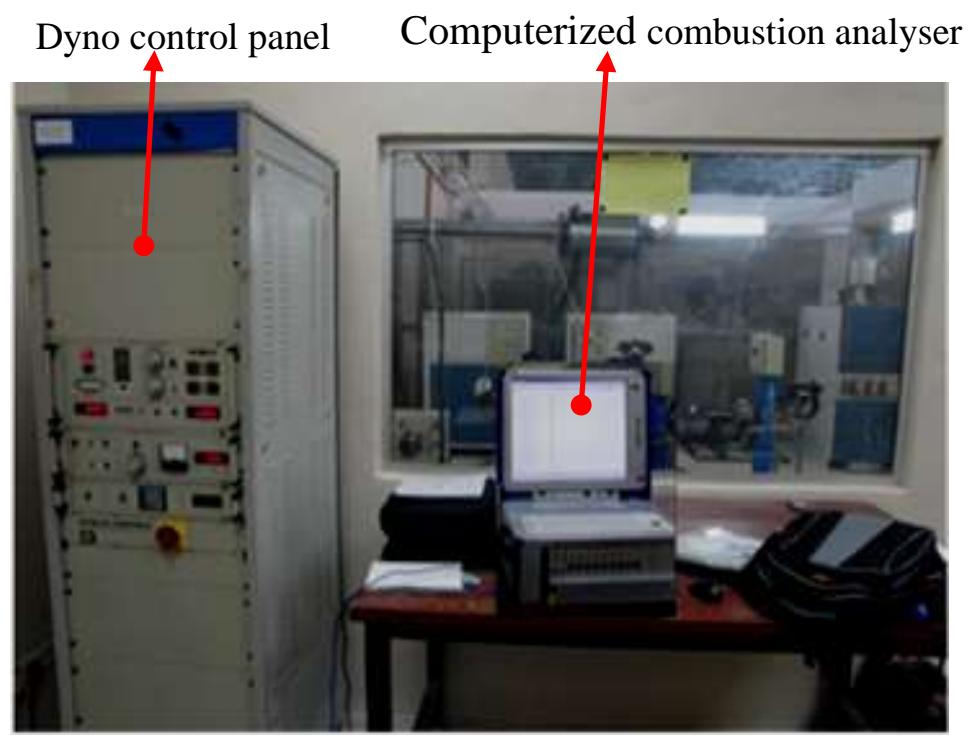

Figure 2. Control room.

\section{Measurements}

The acquired database included in-cylinder pressure against crank angle within a combustion analyser to obtain the indicated mean effective pressure (IMEP) under multi-rated engine speed. The in-cylinder pressure trace was instantaneously measured by using an FGP transducer. The FGP pressure sensor type XPM5-100 bar is installed on the cylinder head to measure the engine cylinder pressure. A special threaded hole was made in the cylinder head to accept the pressure sensor. A Kistler Type 2613B crank angle encoder, mounted at the end of the dynamometer shaft, provides the clock signal for measurement. The crank angle encoder and pressure sensor are connected with a DEWE5000, a computer-based combustion analyser, completed with a data acquisition system. The combustion analyser unit, DEWE5000 is employed for pressure data collection in the crank angle domain. Moreover, measurements were taken for engine torque and actual speed through the dynamometer control panel.

\section{RESULTS AND DISCUSSION}

A one-dimensional gas dynamic model was developed utilizing the GT-Power code for engine performance prediction. The general characteristics of the model set-up process and the model governing equations are abridged and outlined in previous works[2628]. The experimental test-rig was used in order to provide validation data for the baseline engine numerical model. Thereby, the indicated mean effective pressure (IMEP) for the baseline engine model with gasoline fuel has been utilized as a proof. Besides that, the brake torque for the engine has been utilized to assess the numerical results.In Figure 3, the experimental IMEP against engine speed are compared with the computational results. It can be seen that the computational results closely follow the experimental results. The predicted results are in reasonably good agreement with the experimental results (within a maximum relative error of $4 \%$ for IMEP). It is shown that the computational results have the same trends as the experimental results. In spite of 
the deviation between the computational and experimental results, the developed set-up is still capable of describing the engine performance with acceptable coincidence.

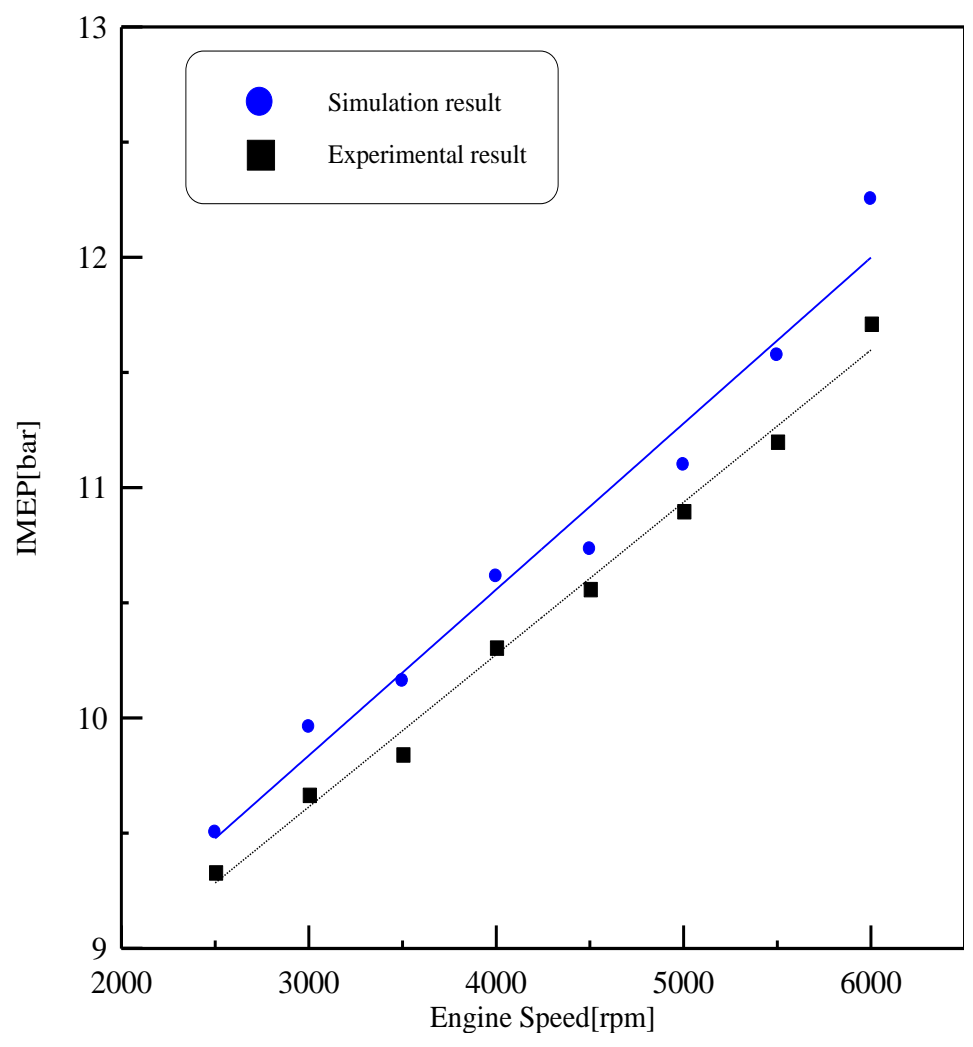

Figure 3.Comparison between experimental and simulated IMEP of tested engine.

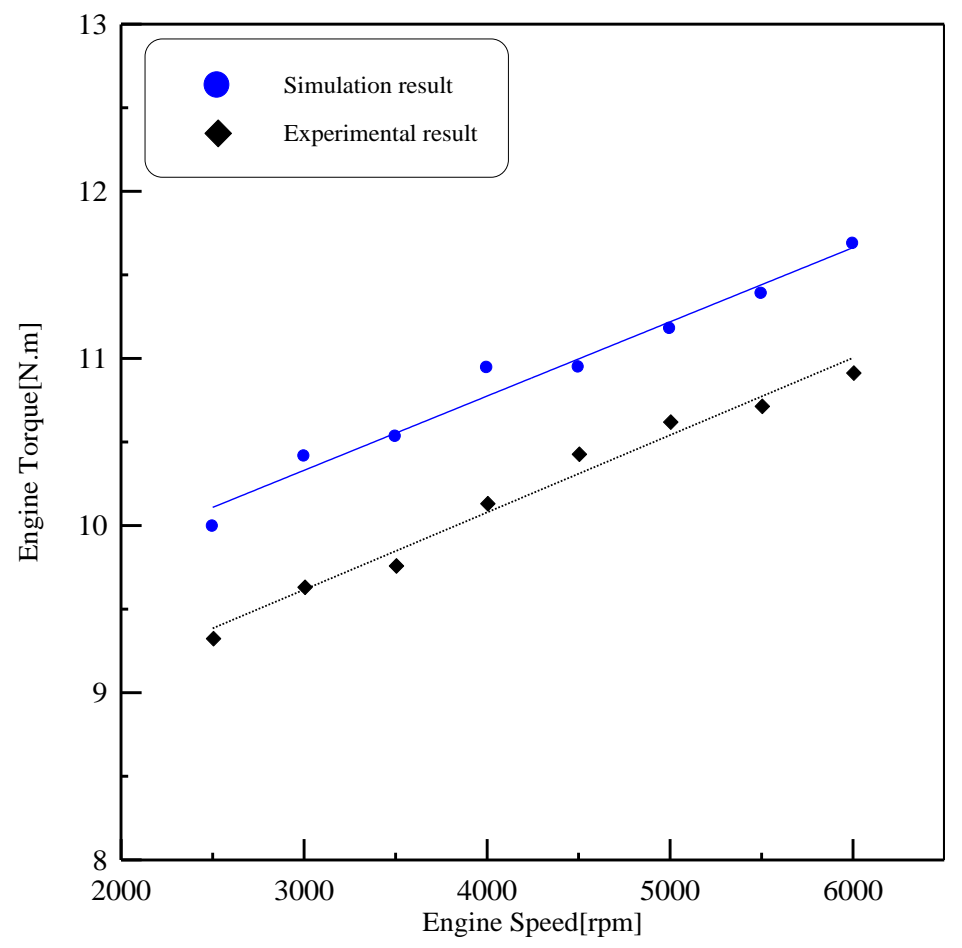

Figure 4.Comparison between experimental and simulated torque of tested engine. 
Figure 4 shows a comparison of the experimental brake torque for the gasolinefuelled engine against engine speed with the computational results. It is shown that the computational results have the same trends as the experimental results. In spite of the large deviation between the computational and experimental results (with a maximum relative error of $7.5 \%$ for the engine brake torque), the adopted model is still capable of describing the engine performance with acceptable coincidence. Obviously, the present test-rig is capable of predicting, with reasonable accuracy, the engine performance of a gasoline SI engine, and then it can be extended to be used for further analysis.

\section{CONCLUSIONS}

In summary, this work has tried to build up a proper test-rig based on a modern motorcycle engine for systematic research and development programs. A small engine test-rig was constructed for an educational and development environment and was found to be capable of achieving similar results to those obtained in a large-scale approved laboratory. The developed test-rig was employed for verification of a numerical model and showed a reasonable matching between the numerical and experimental results. Moreover, it can be confirmed that an acceptable test-rig was developed through comparison with the manufacturer's specification of the tested engine as listed in Table 1. The current test-rig is clearly capable of evaluating, with sufficient accuracy, the performance of a gasoline SI engine, and it can therefore be extended for use in further research and development projects.

\section{ACKNOWLEDGMENT}

The authors would like to thank Universiti Malaysia Pahang for providing laboratory facilities and financial support under projects No. RDU100387.

\section{REFERENCES}

[1] Hushim MF, Alimin AJ, Mansor MF. Effect of intake manifold angle of portfuel injection retrofit-kit to the performances of an SI engine. Applied Mechanics and Materials. 2012;165:31-7.

[2] Environment UN, (UNEP) P. Cleaner motorcycles. Promoting the use of fourstroke engines. 1 January 2006 ed. Nairobi, Kenya: United Nations Environment Programme 2006. p. 12.

[3] Kamil M, Rahman MM, Bakar RA. Integrated simulation model for composition and properties of gases in hydrogen fueled engine. International Journal of Automotive and Mechanical Engineering. 2013;8:1242-155.

[4] Kamil M, Rahman MM, Bakar RA. An integrated model for predicting engine friction losses in internal combustion engines. International Journal of Automotive and Mechanical Engineering. 2014;9:1695-708.

[5] Hamada KI, Rahman MM, Abdullah MA, Bakar RA, A. Aziz AR. Effect of mixture strength and injection timing on combustion characteristics of a direct injection hydrogen-fueled engine. International Journal of Hydrogen Energy. 2013;38:3793-801.

[6] Hamada KI, Rahman MM, Aziz ARA. Influence of engine speed and mixture strength on instantaneous heat transfer for direct injection hydrogen fuelled 
engine. Energy Education Science and Technology Part A: Energy Science and Research. 2012;30:153-72.

[7] Ramasamy D, Yuan GC, Bakar RA, Zainal ZA. Validation of road load characteristic of a sub-compact vehicle by engine operation. International Journal of Automotive and Mechanical Engineering. 2014;9:1820-31.

[8] Cathcart G, Houston R, Ahern S. The potential of gasoline direct injection for small displacement 4-stroke motorcycle applications. SAE Technical Paper; 2004.

[9] Kamil M, Rahman MM, Bakar RA. Performance evaluation of external mixture formation strategy in hydrogen fueled engine. Journal of Mechanical Engineering and Sciences. 2011;1:87-98.

[10] Gharehghani A, Hosseini R, Yusaf T. Investigation of the effect of additives to natural gas on heavy-duty si engine combustion characteristics. Journal of Mechanical Engineering and Sciences. 2013;5:677-87.

[11] Ghobadian B, Najafi G, Nayebi M. A semi-empirical model to predict diesel engine combustion parameters. Journal of Mechanical Engineering and Sciences. 2013;4:373-82.

[12] Izamshah R, Husna N, Hadzley M, Amran M, Shahir M, Amri M. Effects of cutter geometrical features on machining polyetheretherketones (PEEK) engineering plastic. Journal of Mechanical Engineering and Sciences. 2014;6:863-72.

[13] Aziz A, Rashid A, Firmansyah, Shahzad R. Combustion analysis of a CNG direct injection spark ignition engine. International Journal of Automotive and Mechanical Engineering. 2010;2:157-70.

[14] Aziz Hairuddin A, Wandel AP, Yusaf T. Effect of different heat transfer models on a diesel homogeneous charge compression ignition engine. International Journal of Automotive and Mechanical Engineering. 2013;8:1292-304.

[15] Bhaskar K, Nagarajan G, Sampath S. Experimental investigation on cold start emissions using electrically heated catalyst in a spark ignition engine. International Journal of Automotive and Mechanical Engineering. 2010;2:10518.

[16] Kapilan N, Ashok Babu TP, Reddy RP. Improvement of performance of dual fuel engine operated at part load. International Journal of Automotive and Mechanical Engineering. 2010;2:200-10.

[17] Ferguson CR. Internal combustion engines, applied thermosciences: Wiley; 1986.

[18] Rahman MM, Hamada KI, A. Aziz AR. Characterization of the time-averaged overall heat transfer in a direct-injection hydrogen-fueled engine. International Journal of Hydrogen Energy. 2013;38:4816-30.

[19] Rahman MM, Hamada KI, Bakar RA, Maleque MA. Heat transfer analysis inside exhaust port for a hydrogen fueled port injection engine. Advanced Science Letters. 2012;14:239-43.

[20] Pulkrabek WW. Engineering Fundamentals of the Internal Combustion Engine: Pearson New International Edition: Pearson Education, Limited; 2013.

[21] Noor MM, Wandel AP, Yusaf T. A review of MILD combustion and open furnace design consideration. International Journal of Automotive and Mechanical Engineering. 2012;6:730-54.

[22] Ferguson CR. Internal combustion engines, applied thermosciences. 2 ed. New York: John Wiley and Sons, Inc; 2001. 
[23] Heywood JB. Internal combustion engine fundamentals: Mcgraw-hill New York; 1988.

[24] Stone R. Introduction to Internal Combustion Engines: Palgrave Macmillan Limited; 2012.

[25] Ramasamy D, Aik Soon K, Walker-Gitano Briggs H, Zainal ZA. Variation of airflow pattern through dissimilar valve lift in a spark ignition engine. Journal of the Chinese Institute of Engineers, Transactions of the Chinese Institute of Engineers,Series A/Chung-kuo Kung Ch'eng Hsuch K'an. 2013;36:1083-96.

[26] Zamri M, Devarajan R, Mohd Razali H. Small Sedan Aerodynamics Analysis. The 1st National Conference in Mechanical Engineering for Research and Post Graduate Studies,Ncmer. 1 ed. Kuantan: UMP; 2010.

[27] Hamada KI, Rahman MM, Bakar RA. Trend of heat transfer parameters in the in-cylinder of hydrogen fueled engine. 3rd International Conference on Mechanical and Electrical Technology, Dalian, China: ASME digital collection; 2011. p. 681-7.

[28] Hamada KI, Rahman M, Noor M, Kadirgama K, Bakar RA. Influence of Engine Speed and Injection Timings on In-Cylinder Heat Transfer for Port Injection Hydrogen Fueled Engine. NCMER. 2010;2:3-4. 